

\title{
X-33 Hypersonic Aerodynamic Characteristics
}

\author{
Kelly J. Murphy*, Robert J. Nowak*†, Richard A. Thompson*, Brian R. Hollis*† \\ NASA Langley Research Center, Hampton, VA 23681 \\ Ramadas Prabhu** \\ Lockheed-Martin Engineering \& Sciences, Hampton, VA 23681
}

\begin{abstract}
Lockheed Martin Skunk Works, under a cooperative agreement with NASA, will build and fly the X-33, a half-scale prototype of a rocket-based, single-stage-to-orbit (SSTO), reusable launch vehicle $(\mathrm{RLV})$. A 0.007-scale model of the X-33 604B0002G configuration was tested in four hypersonic facilities at the NASA Langley Research Center to examine vehicle stability and control characteristics and to populate an aerodynamic flight database in the hypersonic regime. The vehicle was found to be longitudinally controllable with less than half of the total body flap deflection capability across the angle of attack range at both Mach 6 and Mach 10. At these Mach numbers, the vehicle also was shown to be longitudinally stable or neutrally stable for typical (greater than 20 degrees) hypersonic flight attitudes. This configuration was directionally unstable and the use of reaction control jets (RCS) will be necessary to control the vehicle at high angles of attack in the hypersonic flight regime. Mach number and real gas effects on longitudinal aerodynamics were shown to be small relative to $X-33$ control authority.
\end{abstract}

\section{Nomenclature}

$\mathrm{B}_{\text {Ief }} \quad$ lateral reference length

$\mathrm{C}_{\mathrm{A}}$ axial-force coefficient

$\mathrm{C}_{\mathrm{D}}$ drag-force coefficient

$\mathrm{C}_{\mathrm{L}} \quad$ lift-force coefficient

$\mathrm{C}_{\mathrm{L} 0}$ lift-force coefficient at 0 deg angle of attack

$\mathrm{C}_{1}$ rolling-moment coefficient

$\mathrm{C}_{1 \beta} \quad$ rolling-moment derivative

$\mathrm{C}_{\mathrm{m}} \quad$ pitching-moment coefficient

$\mathrm{C}_{\mathrm{n}}$ yawing-moment coefficient

$\mathrm{C}_{\mathrm{n} \beta} \quad$ yawing-moment derivative

$\mathrm{C}_{\mathrm{N}}$ normal-force coefficient

$\mathrm{C}_{\mathrm{Y}}$ side-force coefficient

$\mathrm{L}_{\mathrm{ref}} \quad$ longitudinal reference length

$\mathrm{p}_{\infty} \quad$ static pressure of free stream, psia

$\mathrm{pt} \quad$ tunnel stagnation pressure, psia

$\mathrm{q}_{\infty} \quad$ free stream dynamic pressure, $\mathrm{psia}$

$\mathrm{Re} / \mathrm{ft}$ free stream unit Reynolds number

$\mathrm{S}_{\text {ref }}$ reference area

$\mathrm{T}_{\infty} \quad$ static temperature of free stream, ${ }^{\circ} \mathrm{R}$

$\mathrm{T}_{\mathrm{t}} \quad$ tunnel stagnation temperature, ${ }^{\circ} \mathrm{R}$

$\alpha \quad$ angle of attack, deg

$\beta \quad$ angle of sideslip, deg

$\delta_{b f} \quad$ body flap deflection, deg

$\delta_{\mathrm{el}} \quad$ elevon deflection, deg

$\Delta \mathrm{C}_{\mathrm{m}}$ increment in pitching-moment coefficient

$\gamma \quad$ ratio of specific heats

$\rho_{2} / \rho_{\infty}$ shock density ratio

Aerospace Technologist, Aerothermodynamics Branch

Aerodynamics, Aerothermodynamics and Acoustic Competency

$\dagger$ Member AIAA

** Senior Aerospace Engineer

\section{Introduction}

As a first step towards development of an operational next-generation reusable launch system, Lockheed Martin Skunk Works (LMSW), under a cooperative agreement with NASA, will build and fly the $\mathrm{X}-33$, a half-scale prototype of a rocket-based, single-stage-to-orbit (SSTO), reusable launch vehicle (RLV). The objective of the X-33 program is to demonstrate key design and operational aspects of an SSTO vehicle in order to reduce the business and technical risks to the private sector in developing a commercially viable RLV system. The X-33 concept has a lifting body shape with two integrated linear aerospike rocket engines and flies a sub-orbital trajectory to simulate important aerodynamic and aerothermodynamic aspects of ascent and re-entry environments for a full-scale RLV. The X-33 vehicle will be launched vertically from a site at Edwards Air Force Base in Southern California and land horizontally at Michael Air Force Base in Utah. Multiple flights are planned to examine vehicle aerodynamic and structural characteristics, thermal protection system (TPS) robustness, and engine performance to validate new technologies with scaleability and traceability to a future RLV.

At the beginning of this decade, the National Aero-Space Plane (NASP/X-30) was an SSTO concept studied by NASA. The NASP configuration was a form of lifting body ${ }^{1}$ with an integrated hypersonic air-breathing propulsion system. The program was terminated in 1994 when it was realized that the high temperature materials and air-breathing propulsion technology necessary to fly the X-30 would take many more years to mature. Based on the Access to Space Study ${ }^{2}$ that followed the termination of the X-30 program, NASA moved forward to 
develop, in partnership with private industry, a rocket-based, single-stage-to-orbit, fully Reusable Launch Vehicle system. NASA solicited proposals from the aerospace industry in 1994 to design and build the X-33, an advanced technology demonstrator that would lead to development of a single-stage-toorbit RLV system which would begin flying in the 2005 time-frame. Three companies, LockheedMartin, McDonnell Douglas, and Rockwell submitted competitive configurations for the X-33. For 15 months beginning in the Spring of 1995, personnel in Langley's Aerothermodynamics Branch led an intensive testing and evaluation effort of the three concepts, designated as Phase I of the X-33 program. Based on information obtained in Phase I, the three companies were required to submit proposals for evaluation, which contained both the technical and financial feasibility of their configurations. On July 2, 1996, it was announced that the Lockheed-Martin Skunk Works had been selected to build and fly the $\mathrm{X}-33$.

The X-33 vehicle, currently being built by Lockheed Martin in Palmdale, California, is a 63-foot long lifting body with 20-degree dihedral canted fins, two windward side body flaps, and twin vertical tails (Fig. 1). The maximum body span between canted fin tips is 76 feet. The external body shape is defined by the internal fuel tank structure; a single liquid oxygen tank defines the forward portion of the body and a dual-lobed liquid hydrogen tank defines the aft portion of the vehicle. Two linear aerospike engines will propel the vehicle to Mach numbers of 10 or greater. A typical X-33 trajectory is presented in Figure 2.

Phase II testing began at Langley in the late fall of 1996 to provide benchmark data across the speed regime to develop a flight database for the final $\mathrm{X}-33$ configuration. The focus of this paper will be the work done to characterize the hypersonic aerodynamics of the X-33 vehicle. Experimental data from four hypersonic facilities at Langley are presented, along with supporting supersonic data from Langley's Unitary Plan Wind Tunnel as well as CFD calculations performed to complement wind tunnel results at selected Mach numbers and angles of attack.

\section{Apparatus and Test}

\section{Model Description}

All experimental data presented were obtained with a 0.007 -scale metallic force-andmoment model designed and fabricated in-house at NASA Langley. The outer-mold-line geometry was obtained from Lockheed Martin Skunk Works and is designated as the 604B0002G configuration. This is aerodynamically similar to the $604 \mathrm{~B} 0002 \mathrm{~F}$ (referred to as "Rev F"), configuration which was used to generate the aerothermodynamic database for the $\mathrm{X}$ -
$33^{3,4}$, the only difference being minor modifications to the small protrusions on the aft upper surface of the vehicle and the canted fin body fillet. ${ }^{5}$ The reference areas and lengths used to calculate aerodynamic coefficient data for the full-scale vehicle and the 0.007 -scale model are presented in Table 1.

The model was fabricated from stainless steel and included removable canted fins, body flaps, vertical tails, and engine blocks. Numerous canted fins and vertical tails were made, as both rudder and elevon deflections were integral to these structures. Body flap deflections were obtained by using individually-machined tabbed flaps with the given deflection. Fin, flap, and engine off-blocks were machined and fitted to the model for configuration build-up studies. The model's body and base section were designed in such a way as to receive either a straight sting or a 30 degree blade strut support. The blade, designed for use at higher angles of attack, exits the leeside of the model. This allows the windward side of the linear aerospike engine nozzle to be preserved. The half-inch straight sting significantly impacts base region nozzle geometry, but provides a minimally disturbed leeside flow at low angles of attack. Different facilities permitted varying degrees of overlap in the angle-of-attack range for the blade and sting configurations. Photographs of the baseline model, both sting and blade-mounted, are shown in Figure 3.

\section{Test Parameters}

A summary of the test matrices for all the hypersonic aerodynamic data, including information about model parametrics and support structure for tests in each facility, is presented in Table 2. The model angle of attack ranged from -4 to $50 \mathrm{deg}$ with the model mounted on a straight sting as well as on a blade strut for selected portions of this angle of attack range. Deflectable control surfaces included body flaps $(-15$ to $+30 \mathrm{deg})$, elevons $(-10$ to $+30 \mathrm{deg})$, and rudders (no deflections tested hypersonically), with increments shown in Table 2 . The majority of runs were made with only one control surface deflected to obtain both a symmetric control surface increment (the assumption of symmetric superposition was spot-checked) and an asymmetric aileron increment. Data were not obtained for coupled control surface deflections. In order to understand the individual contributions of the various aerodynamic surfaces to vehicle trim characteristics, a configuration build-up study was conducted to complement the existing hypersonic aerodynamic database. Configurations compared were the baseline vehicle, the baseline without canted fins, the baseline without body flaps, the baseline without fins and flaps (basic body with aerospike engine nozzle and vertical tails), and the baseline without fins, flaps, and engine nozzle. 


\section{Facility Description}

Four hypersonic facilities at LaRC were used to generate aerodynamic data: the 20-Inch Mach 6 Air Tunnel, the 31-Inch Mach 10 Air Tunnel, the 20-Inch Mach $6 \mathrm{CF}_{4}$ Tunnel, and the 22-Inch Mach 20 Helium Tunnel. Reference 6 contains a detailed description of these facilities, their history and their capabilities, and a brief summary of pertinent information is also given in tabular form below. Nominal flow conditions for the tests run can be found in Table 3 .

LaRC 20-Inch Mach 6 Air Tunnel

$\begin{array}{ll}\text { Type: } & \text { Hypersonic blow-down } \\ \text { Test Medium: } & \text { Heated, dried, filtered air } \\ \text { Nozzle, throat: } & \text { 2-D contoured,0.4x 20.5in. } \\ \text { Run times: } & 2 \text { minutes } \\ \text { Mach Range: } & 5.8 \text { to } 6.1 \\ \text { Stagnation Pres. Range: } & 30 \text { to } 500 \mathrm{psia} \\ \text { Stagnation Temp.Range: } & 750 \text { to } 1000^{\circ} \mathrm{R} \\ \text { Unit Reynolds No. Range: } 0.5 \text { to } 8 \text { million } / \mathrm{ft} \\ \text { Shock Density Ratio: } \quad 6\end{array}$

LaRC 20-Inch Mach $6 \mathrm{CF}_{4}$ Tunnel

Type: Hypersonic blow-down

Test Medium: $\quad$ Heated, dried, filtered $\mathrm{CF}_{4}$

Nozzle ,throat: Axisymmetric, 0.45 in. dia.

Run times: 1 minute

Mach Range: $\quad 5.9$ to 6

Stagnation Pres. Range: 100 to 2000 psia

Stagnation Temp. Range: 1100 to $1400^{\circ} \mathrm{R}$

Unit Reynolds No. Range: 0.05 to $0.7 \mathrm{million} / \mathrm{ft}$

Shock Density Ratio:

12

LaRC 31-Inch Mach 10 Air Tunnel

$\begin{array}{ll}\text { Type: } & \text { Hypersonic blow-down } \\ \text { Test Medium: } & \text { Heated, dried air } \\ \text { Nozzle, throat: } & \text { 3-D contoured,1.1 in. square } \\ \text { Run times: } & 1 \text { minute } \\ \text { Mach Range: } & 9.7 \text { to } 10 \\ \text { Stagnation Pres. Range: } & 350 \text { to } 1450 \text { psia } \\ \text { Stagnation Temp. Range: } & 1800{ }^{\circ} \mathrm{R} \\ \text { Unit Reynolds No. Range: } 0.5 \text { to } 2.1 \text { million } / \mathrm{ft} \\ \text { Shock Density Ratio: } & 5.3\end{array}$

LaRC 22-Inch Mach 20 Helium Tunnel

Type: Hypersonic blow-down

Test Medium: $\quad$ Filtered, dried helium

Nozzle, throat: $\quad$ Axisymmetric, 0.62 in. dia.

Run times:

Mach Range:

40 seconds

Stagnation Pres. Range: 300 to 3300 psia

Stagnation Temp. Range: $530^{\circ} \mathrm{R}$

Unit Reynolds No. Range: 2.4 to 22 million/ft

Shock Density Ratio: 4
Data were obtained in the Mach 6 and Mach 10 facilities to examine the effect of increasing Mach number on the aerodynamic coefficients. Comparisons of data between the Mach 6 air and $\mathrm{CF}_{4}$ tunnels provide, through an increase in shock density ratio, an indication of the significance of real gas effects for the configuration. Data obtained in the Mach 20 Helium Tunnel were used in conjunction with Mach 6 and 10 data to assess the validity of helium simulation for high Mach number liftingbody aerodynamics.

\section{Instrumentation and Data Reduction}

Three aerodynamic forces and three aerodynamic moments were measured using standard Langley 6-component strain gage balances. Five different 9/16-in. diameter, water-cooled balances were used for testing in the hypersonic facilities to accommodate different loadings and to check data repeatability. Balance zeros were monitored before and after each run, and balance components were monitored for excessive drift due to large thermal gradients across the balance gages. Balance data were acquired in a pitch/pause manner in all facilities, with a pause typically lasting 3-5 seconds at a given attitude. Data were averaged over 1 second with an acquisition rate of 20 samples/second. The model attitude was measured at the strut head and corrected post-run for sting deflections under load. Regardless of support system or orientation, the model was kept well within the highly uniform core $(< \pm 1 \%$ pitot pressure variation) as defined by tunnel flowfield surveys. Cavity pressure and limited base pressure measurements were obtained with external tubing and off-board transducers. The level and variation of the pressure measurements was monitored to verify that no corrections needed to be made to the aerodynamic data. The hypersonic data presented were obtained without the use of any boundary layer tripping devices.

The only uncertainty applied to the data is a conservative balance precision error of $\pm 0.5 \%$ of the full-scale loads. The quoted balance accuracies are generally much smaller, but in the presence of high temperature effects on the balance as well as other tunnel and model variations (such as flow nonuniformity and model attitude), this conservative estimate seems a physically reasonable upper bound. A listing of balances used in this study and the uncertainties for representative flow conditions are shown in Tables 4 and 5.

\section{Computational Methods}

To complement the experimental database and to provide data at flight conditions, CFD calculations were performed for selected configurations over a range of angles of attack and Mach numbers. Two 
finite-volume, Navier-Stokes solvers, LAURA and GASP, and an inviscid Euler code, FELISA, were used to obtain aerodynamic data. Computational results at Mach 6 and 10 will be presented with the experimental data in subsequent sections. A thorough discussion of CFD codes, models, and data is presented by Hollis in Reference 9 .

\section{$\underline{\text { Results and Discussion }}$}

\section{Hypersonic Aerodynamic Characteristics}

The longitudinal characteristics of the baseline $\mathrm{X}-33$ configuration are shown in Figures 4(a)-4(f), with both experimental and computational results for Mach 6 and 10 plotted versus vehicle angle of attack. Low angle of attack $(\alpha<25 \mathrm{deg})$ data were obtained with the model supported on a straight sting; high angle of attack $(\alpha>25 \mathrm{deg})$ data were obtained with the model supported on a blade sting. The experimental results presented in Fig. 4 are curve fits to data representative of the mean value of data obtained throughout the test program. Data repeatability/uncertainty and support system effects will be discussed in subsequent sections of this paper.

Lift coefficient data for Mach 6 and 10 are presented in Fig. 4(d). The data exhibit nearly linear behavior with a lift curve slope, $\mathrm{C}_{\mathrm{L \alpha}}$, of approximately .08 between $\alpha=8$ and $36 \mathrm{deg}$. The highest degree of non-linearity occurs at angles of attack greater than $40 \mathrm{deg}$. $\mathrm{C}_{\mathrm{L} 0}$ values are identical for Mach 6 and 10 and are negative due to negative fin incidence. At angles of attack greater than $8 \mathrm{deg}, \mathrm{C}_{\mathrm{L}}$ values for Mach 6 are slightly higher than for Mach 10 , which is an expected trend with Mach number. ${ }^{7,8}$ The maximum deviation between data sets occurs at $\alpha=20 \mathrm{deg}$, which corresponds to the maximum differences in both the normal and axial forces on the configuration (Figs. 4(a) and 4(b)). Computational values of $C_{N}$ and $C_{A}$ across the angle-of-attack range show good agreement in trend and magnitude with experimental data. Data sets for $C_{D}$ and $L / D$ (Figs. 4(e) and 4(f)) exhibit similar Mach number effects with maximum deltas between Mach 6 and 10 occurring at $\alpha=20 \mathrm{deg}$. The Mach 6 experimental data gives a maximum $L / D$ value of 1.25 at $\alpha=20$ $\mathrm{deg}$, while $L / D_{\max }$ at Mach 10 is 1.2 at $\alpha=24 \mathrm{deg}$.

Pitching moment characteristics are shown in Fig. 4(c). Both Mach 6 and 10 data show a configuration that is longitudinally unstable (positive $\mathrm{C}_{\mathrm{m} \alpha}$ ) for $\alpha<10 \mathrm{deg}$, and longitudinally stable (negative $C_{m \alpha}$ ) for $\alpha>24 \mathrm{deg}$. Experimental data show the vehicle to be more stable at Mach 10 than Mach 6; computational data show the same trend but show this difference in stability level to be noticeably smaller. The greatest differences in $C_{m}$ values between Mach 6 and 10 experimental data and between experimental and computational data occur at the highest angles of attack. The difference between Mach 6 and 10 data at $\alpha=48 \mathrm{deg}$ is approximately
.005 ; the difference between experiment and CFD at this same angle of attack is .006 and .003 for Mach 6 and 10 respectively. $C_{m}$ differences become smaller as the angle of attack decreases. Although the pitching moment curves exhibit an unexplained crossover in the mid-alpha range (20-30 deg), this behavior is also exhibited, although at a higher angle of attack, by the existing CFD data set. Reference 9 shows this crossover to be a continuous function of Mach number by additional CFD calculations at Mach numbers between 4 and 10. Since definition of longitudinal trim characteristics are of great importance for hypersonic reentry trajectories, the pitching moment database will be more thoroughly discussed in light of data repeatability and control authority in the sections that follow.

Figures 5(a) and 5(b) present the lateraldirectional stability characteristics $C_{1 \beta}$ and $C_{n \beta}$ for the $\mathrm{X}-33$ vehicle for Mach 6 and 10 . Both experimental data sets show the vehicle is stable in roll (negative values of $\mathrm{C}_{1 \beta}$ ) for all but the lowest angles of attack tested $(\alpha<4$ deg). The vehicle demonstrates positive dihedral effect, and roll stability increases nearly linearly as the angle of attack increases and the wing dihedral becomes more effective. $C_{n \beta}$ is nearly a constant negative value across the angle of attack range for Mach 6 and 10 indicating the vehicle is directionally unstable, which is common for these types of aerospace configurations. The small twin vertical tails on the aft upper surface do little to affect yaw stability, especially at typical hypersonic re-entry attitudes when they are entirely shielded from the freestream flow behind the body. Therefore, the use of reaction control jets (RCS) will be necessary to control the vehicle. For this reason, no rudder deflections were examined at Mach 6 and 10, and no further discussion of lateral-directional characteristics will be presented.

\section{Longitudinal Control Authority}

The body flap effectiveness, $\Delta \mathrm{C}_{\mathrm{m}}$, for four flap deflection angles at vehicle angles of attack from 20 to $50 \mathrm{deg}$ for Mach 6 and 10 is presented in Figure 6(a). These curves represent simultaneous deflection of both body flaps and have been constructed by doubling the $\Delta \mathrm{C}_{\mathrm{m}}$ measured from a single body flap deflection. For several deflections this superposition assumption was checked against true symmetric deflections, and the results were indistinguishable on a physically relevant scale. Cross-talk between the flaps is not expected, as they are not in proximity to each other. The increment in $\mathrm{C}_{\mathrm{m}}$ due to deflecting the body flaps up $\left(\delta_{\mathrm{bf}}=-15 \mathrm{deg}\right)$ is positive and increases with angle of attack, appearing to asymptote to a constant value at the highest angles of attack. The remaining sets of data represent down-flap deflections of 10,20 , and $30 \mathrm{deg}$. A 10-deg flap deflection shows a negative pitch increment that smoothly increases with angle of attack to a nearly constant value of approximately -0.02 for both Mach numbers. 
There appears to be a slight decrease in flap effectiveness for this case at the highest angles of attack. This could signify the beginning of a separation of the incoming laminar boundary layer at the flap hinge line. Recalling the baseline pitching moment curves in Fig. 4(c), one can see that a 10-deg flap deflection produces more than twice the control authority needed to trim the vehicle.

As the flap is further deflected down to 20 and $30 \mathrm{deg}$, flap effectiveness becomes very non-linear. To explain this behavior, experimental heating data, surface and flow field visualization techniques, and computational flow field solutions were used in conjunction with the aerodynamic data. At Mach 6 , Horvath $^{3}$ observed a complex heating pattern on the windward surface of the 20-deg flap and a well-defined disturbance in accompanying oil-flow visualizations. Schlieren photography at the same conditions clearly show interaction between the vehicle's bow shock and flap shock. Computations by Hollis ${ }^{10}$ show that this disturbance on the flap is due to the impingement of an expansion fan resulting from the bow shock/flap shock interaction. The resulting decrease in surface pressures on the flap appears to be the cause of the non-linear characteristics for larger flap deflection angles. The fact that the surface pressure distribution on the flaps is influenced by the relative location of the bow and flap shocks may explain why slightly greater differences are observed between Mach 6 and 10 pitch increments with increasing flap deflection. As shown in Fig. 6(a), laminar CFD calculations also show these non-linear effects on pitching moment increments. Data show that the decrease in control effectiveness due to this shock/shock interaction begins at a lower angle of attack for the 30-deg flap deflection, most likely owing to the steeper flap shock associated with the larger flap deflection. The aforementioned aeroheating results showed this flow structure to be highly dependent on the state of the boundary layer when comparing laminar and turbulent heating distributions (turbulent results were obtained by physically tripping the boundary layer upstream of the deflected flap). Over the Reynolds number range tested, it is believed that all force and moment data, and therefore body flap increment data, were obtained for laminar conditions only. Increments obtained computationally for laminar flow also agree well with the experimental data. Based on turbulent heating results where these disturbances are much less severe, it seems reasonable to believe that flap effectiveness would increase for turbulent flight cases.

The elevon effectiveness is shown in Figure 6(b) and again is the result of superposition of a single deflected surface. The elevons produce smaller pitching moment increments than the body flaps due to a smaller surface area. The $\mathrm{C}_{\mathrm{m}}$ increments due to increases in elevon deflection exhibit less nonlinearity than the body flaps. Thus there is no evidence of a shock/shock interaction affecting the surface pressure distributions as was seen for the body flaps. Elevons at the highest negative deflection $\left(\delta_{\mathrm{el}}\right.$ $=-30 \mathrm{deg})$ show a reduced increment $\left(\Delta \mathrm{C}_{\mathrm{m}}\right.$ per degree of deflection) across the angle of attack range. The positive elevon deflections show much more linear behavior with increasing deflection and increasing angle of attack. The slight decrease in effectiveness at the highest angles of attack for $\delta_{\mathrm{el}}=20$ and $30 \mathrm{deg}$ may be due to the effects of a larger laminar separation at the hinge line.

\section{Wind Tunnel Database}

As shown in the preceding section, there is ample control surface authority to provide trim control through the hypersonic portion of the X-33 trajectory. However, there has been much scrutiny, from an academic viewpoint, of the pitching moment results generated both experimentally and computationally at Mach 6 and 10 . Some of the differences found are not easily explainable from a fluid dynamics perspective. A further discussion of the hypersonic database, in light of repeatability, uncertainty, and control authority, will provide the reader additional insight into pitching moment phenomena and confidence about the data set as a whole.

Figure 7(a) shows numerous pitching moment data points generated for the baseline configuration for Mach 6 and 10 with both sting and blade mount supports. Two shaded gray bands are drawn to show the extent of $\mathrm{C}_{\mathrm{m}}$ variation for both Mach numbers. It is important to note that for all data presented, the range of $C_{m}$ values for a given angle of attack are within the $\pm 0.5 \%$ accuracy previously discussed. The variation in the Mach 6 data set is less than $\pm 0.25 \%$ throughout the angle of attack range, and model support appears to have no influence on pitching moment trends. The Mach 10 data set shows a larger scatter in the data set and more noticeable differences between the sting and blade mounts across the angle-of-attack range but remain with the $\pm 0.5 \%$ accuracy band. The total temperature in the Mach 10 facility is twice that of the Mach 6 facility, and although great care was taken to monitor and minimize temperature effects, unavoidable thermal gradients across the model and balance lead to higher uncertainty on measurements at Mach 10. The differences between the sting and blade data observed in Mach 10 across the angle of attack range are not fully understood, but they are quite small. The data presented in Figure 7(a) also represent runs on multiple balances in upright and inverted orientations from numerous tunnel entries. Thus the general pitching moment trends observed for Mach 6 and 10 were shown to be repeatable. Figure 7 (b) revisits body flap control authority (only Mach 6 data shown) relative to the baseline Mach 6 and 10 data sets presented in Fig 7(a). As can be seen in this figure, the observed differences on experimentally measured pitching moment data at Mach 6 and 10 correspond to 
only 2-3 deg of body flap deflection. This increment is a small percentage of the total flap deflection available to control the vehicle at hypersonic conditions.

Another means of checking the validity of the hypersonic pitching moment database is comparison to high supersonic Mach number data. A great deal of testing was done at NASA Marshall's (MSFC) Trisonic Facility to populate the transonic/supersonic database for the $\mathrm{X}-33 .^{5}$ Additional tests are also planned for late Fall 1999 in Lockheed-Martin's Vought Facility to obtain high Reynolds number data in these flight regimes. However, the data generated at MSFC were not at angles of attack high enough for comparison with the hypersonic database. Therefore it was decided that a brief entry of the baseline configuration in LaRC's Unitary Plan Wind Tunnel (UPWT) would provide additional high supersonic data up to $\alpha=40 \mathrm{deg}$ with the LaRC 0.007-scale model (eliminating model/support variation) to support the hypersonic database. A detailed discussion of the UPWT is found in Ref. 10. Nominal flow conditions for this series of tests were the following: $M=4.63, \mathrm{q}_{\infty}=1.5 \mathrm{psi}$, $\mathrm{p}_{\infty}=0.1 \mathrm{psi}, \mathrm{T}_{\infty}=115^{\circ} \mathrm{R}$, and $\mathrm{Re} / \mathrm{ft}=2 \times 10^{6}$. The pitching moment data obtained from these tests, shown in Fig. 8, compares well with trends seen in the Mach 6 and exhibits the "cross-over" seen in the hypersonic data and predicted by the CFD. Supporting inviscid and viscous CFD calculation at a Mach number of 4.63 show excellent agreement with experimental data from the UPWT.

\section{Additional Hypersonic Simulation Data}

NASA Langley has two unique facilities that allow simulation of very high Mach number flows $(\mathrm{M}=17-20)$ : the 20-Inch Mach $6 \mathrm{CF}_{4}$ Tunnel and the 22-Inch Mach 20 Helium Tunnel. Both $\mathrm{CF}_{4}$ and Helium have $\gamma$ values different from ideal air, and the effect and relevance of this variation on predictions of vehicle aerodynamics will be shown.

The 20-Inch Mach $6 \mathrm{CF}_{4}$ tunnel uses a heavy gas with a lower $\gamma(1.22)$ than ideal air to simulate the reduced $\gamma$ of a real gas (due to dissociation within the shock layer) at hypervelocity conditions. (Note that actual real gas chemistry is not simulated in this facility.) Due to the increased shock density ratio, a Mach 6 condition in $\mathrm{CF}_{4}$ provides approximately a Mach 17-20 flight simulation ${ }^{6}$. Schlieren photographs (Figs 9(a) and (b)) of the $X-33$ configuration at $\alpha=48 \mathrm{deg}$ in Mach 6 air and Mach $6 \mathrm{CF}_{4}$ clearly show the decrease in shock stand-off distance due to the increased shock density ratio in $\mathrm{CF}_{4}$. "Real gas effects" during the re-entry portion of the Shuttle's flight trajectory proved to be significant and were predicted, postflight, using $\mathrm{CF}_{4}$ data. With a maximum Mach number of only 10 , real gas phenomena are not expected for the $\mathrm{X}-33$ 's sub-orbital flight. $\mathrm{CF}_{4}$ data for the $X-33$ will be used to gage the significance of real-gas effects for an X-33 derived RLV, which will fly a higher Mach number re-entry trajectory, and therefore are a valuable part of the $\mathrm{X}-33$ hypersonic database.

The 22-Inch Mach 20 Helium tunnel uses purified helium which behaves as an ideal gas, but with a higher $\gamma(1.67)$ than air. The primary advantage of testing in this facility is that high Mach number flows can be generated without heating the gas. Thus low stagnation temperatures are produced which allow the use of inexpensive, rapid-prototype, plastic models for testing. X-33 testing in helium will provide insight into the nature of air-helium simulation techniques for future RLV testing.

Figures 10(a)-10(c) present lift, drag, and pitching moment coefficients obtained in $\mathrm{CF}_{4}$ and helium as compared with the previously discussed Mach 6 and 10 air data to examine the effects of Mach number and shock density ratio on longitudinal aerodynamics. There appears to be little effect of $\gamma$ or Mach number on the integrated quantities of lift and drag as seen in Figures 10(a) and 10(b). However, the pitching moment at high angles of attack shows a much greater sensitivity to these parameters. For $\alpha>35$ deg the $C_{m}$ data in helium become unstable and more nose-up than the air data. The $\mathrm{CF}_{4}$ data shows the opposite trend, with the vehicle becoming more longitudinally stable and more nose-down as compared to both the Mach 6 and 10 data sets. The pitching moment values and the stability levels seem to have a consistent trend with decreasing $\gamma$ (Note that $\gamma$ for Mach 10 air is slightly below that of the ideal value of 1.4 due to the high enthalpy of the Mach 10 facility.) Figure $10(d)$ also supports these trends, showing inviscid calculations for Mach 6 and 10 air, Mach $6 \mathrm{CF}_{4}$ and Mach 20 helium by Prabhu. ${ }^{11}$ These calculations (shown in Ref. 9 to be in very good agreement with viscous results for air and $\mathrm{CF}_{4}$ pitching moment predictions) clearly show the unstable pitch-up in helium and the increase in stability and pitch-down in $\mathrm{CF}_{4}$ at high angles of attack. Figure 10(e) shows the effect of helium and $\mathrm{CF}_{4}$ simulations on body-flap effectiveness for flap deflections of 10 and $20 \mathrm{deg}$. As a general trend, helium tends to under-predict flap effectiveness at higher angles of attack. Therefore, testing in the helium tunnel should provide a conservative estimate of vehicle control authority. The $\mathrm{CF}_{4}$ flap deflection data tends to show a more effective flap, leading to more control authority with real gas effects. While real gas effects for this configuration, as simulated by the $\mathrm{CF}_{4}$ tunnel, were shown to be more significant than Mach number effects, they are still quite small in comparison to those previously observed for the Shuttle.

\section{Configuration Build-Up Studies}

In order to understand the individual contribution of the various aerodynamic surfaces to vehicle trim characteristics, an extensive configuration build-up 
study was conducted to complement the existing hypersonic aerodynamic database. Five configurations were tested: baseline, baseline without flaps, baseline without fins, baseline without flaps and fins, and baseline without flaps, fins, and engine nozzle. The aerospike engine nozzle produced no pitching moment increment for any condition tested due to very low pressures in the wake region, and so no data are presented for this configuration. Figure 11 shows the pitching moment contribution of the first 4 configurations over an angle of attack range of 20 to $50 \mathrm{deg}$ for Mach 6 and 10 . While the baseline configuration is slightly stable, the body alone (baseline without flaps and fins) is highly unstable. It is the presence of the flaps and fins, with nearly equal contributions, that stabilizes the vehicle over this angle of attack range. For both Mach 6 and 10, the flap and fin $C_{m}$ increments add linearly to the body alone to produce the baseline curve, which indicate that interactions between these surface and the body are not significant contributors to the pitching moment. Prior to these configuration build-up studies, it was thought that differences in the flow fields around the flaps, fins or engine nozzle (possibly suggesting a flow disturbance or partial blockage) could be the cause of the variation in pitching moment between Mach 6 and 10. Figure 11 clearly shows that the differences observed between Mach 6 and 10 baseline are also present for the body alone, and are not caused by the flaps or fins at high angle of attack. While the configuration build-up studies did not reveal the cause of Mach number effects on pitching moment characteristics, it identified the body as the source. This information provides the focus for future computational and experimental investigations if a complete understanding of Mach number effects becomes necessary for this configuration.

\section{Concluding Remarks}

A 0.007 -scale model of the X-33 $604 \mathrm{~B} 0002 \mathrm{G}$ configuration was tested in four hypersonic facilities at the NASA Langley Research Center to examine vehicle stability and control characteristics. The vehicle was shown to be longitudinally stable or neutrally stable for angles of attack greater than $20 \mathrm{deg}$ and was found to be longitudinally controllable with less than half of the total body flap deflection capability across the angle of attack range at both Mach 6 and Mach 10. The configuration was shown to be directionally unstable, and the use of reaction control jets (RCS) is necessary to control the vehicle at high angles of attack. The vehicle pitching moment data for the baseline configuration showed an unexpected crossover trend with Mach number that, while not completely understood from a fluid-dynamics perspective, is supported by CFD calculations, high supersonic data, and hypersonic configuration build-up data. Both Mach number and real gas effects on longitudinal aerodynamics were shown to be small relative to X-33 control authority.
The hypersonic aerodynamic data generated at Langley has been used to populate the flight database for the $X-33$ vehicle. This database will be used to design the flight control laws and to optimize X-33 flight trajectories for demonstration of RLV technologies.

\section{Acknowledgements}

The authors wish to thank the many technicians and engineers at NASA LaRC and the Aerodynamics Team at Lockheed-Martin Skunk Works without whose help this work would not have been possible.

\section{References}

1. Reed, R. D.: Wingless Flight, The Lifting Body Story. NASA SP-4220, 1997.

2. Bekey, I., Powell, R., and Austin, R., "NASA Studies Access to Space," Aerospace America, May 1994 , pp. 38-43

3. Horvath, T. J., Berry, S. A., Hollis, B. R., Liechty, D. S., Hamilton, H. H., and Merski, N. R.: "X-33 Experimental Aeroheating at Mach 6 Using Phosphor Thermography," AIAA 99-3558, June 1999.

4. Hollis, B. R., Horvath, T. J., Berry, S. A., Hamilton, H. H., and Alter, S. J.: "X-33 Computational Aeroheating Predictions and Comparisons with Experimental Data." AIAA 993559, June 1999.

5. Reasor, J. S., Ramsey, J. F.: "A Comparison of Wind Tunnel Data Taken For the X33 604B0002F/G Configuration," LMSW 604AERO5046, June 1998.

6. Micol, J. R.: "Langley Aerothermodynamic Facilities Complex: Enhancements and Testing Capabilities," AIAA 98-0147, January 1998.

7. Micol, J. R.: "Experimental and Predicted Aerodynamic Characteristics of a Proposed Assured Crew Return Vehicle (ACRV) Lifting-Body Configuration," AIAA 90-1403, June 1990.

8. Brauckmann, G. J., Paulson, J. W. Jr., Weilmuenster, K. J.: "Experimental and Computational Analysis of Shuttle Orbiter Hypersonic Trim Anomaly," Journal of Spacecraft and Rockets, Vol. 32, No. 5, pp. 758-764, September-October 1995.

9. Hollis, B. R., Thompson, R. A., Murphy, K. J., Nowak, R. J., Riley, C. J., Wood, W. A., Alter, S. J., and Prabhu, R.: "X-33 Aerodynamic and Aeroheating Computations for Wind Tunnel and Flight Conditions," AIAA 99-4163, August 1999

10. Jackson, C. M., Corlett, W. A., and Monta, W. J.: "Description and Calibration of the Langley Unitary Plan Wind Tunnel," NASA TP-1905, November 1981.

11. Prabhu, R.: "A Computational Study of an X-33 Configuration at Hypersonic Speeds," NASA CR1999-209366, July 1999. 
Table 1. Reference Dimensions

\begin{tabular}{|l|c|c|}
\cline { 2 - 3 } \multicolumn{1}{l|}{ Dimension } & Full Scale & $\mathbf{. 0 0 7 - s c a l e}$ \\
\hline Sref & $1608 \mathrm{ft}^{2}$ & $11.346 \mathrm{in}^{2}$ \\
\hline Lref & $63.2 \mathrm{ft}$ & $5.309 \mathrm{in}$ \\
\hline Bref & $36.6 \mathrm{ft}$ & $3.074 \mathrm{in}$ \\
\hline c.g.ref $(66 \%)$ & $41.7 \mathrm{ft}$ & $3.506 \mathrm{in}$ \\
\hline
\end{tabular}

Table 2. Summary of Test Parametrics

\begin{tabular}{|c|c|c|c|c|}
\hline Configuration & $\begin{array}{l}\text { 20" Mach 6 } \\
\text { Air }\end{array}$ & 31" Mach 10 & $\begin{array}{c}20 " \text { Mach } 6 \\
\text { CF } 4\end{array}$ & 22" Mach 20 \\
\hline Baseline & Sting/Blade & Sting/Blade & Sting/Blade & Sting \\
\hline$-15^{\circ}$ body flap & Sting/Blade & Blade & Blade & 2 \\
\hline$+10^{\circ}$ body flap & Sting/Blade & Blade & Blade & Sting \\
\hline$+20^{\circ}$ body flap & Sting/Blade & Blade & Blade & Sting \\
\hline$+30^{\circ}$ body flap & Sting/Blade & Blade & Sting/Blade & Sting \\
\hline$-30^{\circ}$ elevon & Sting/Blade & Blade & Blade & Sting \\
\hline$-20^{\circ}$ elevon & Sting/Blade & Blade & Blade & Sting \\
\hline$-10^{\circ}$ elevon & Sting/Blade & Blade & 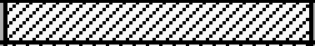 & Sting \\
\hline$+10^{\circ}$ elevon & Sting/Blade & Blade & $\mathrm{Hel} 2$ & Sting \\
\hline$+20^{\circ}$ elevon & Sting/Blade & Blade & $\mathrm{El} \angle 2)$ & Sting \\
\hline$+30^{\circ}$ elevon & Sting/Blade & Blade & $\mathrm{Ez} Z$ & Sting \\
\hline Baseline -Fins & Sting/Blade & Blade & \begin{tabular}{|c|} 
Blade \\
\end{tabular} & Sting \\
\hline Baseline -Flaps & Sting/Blade & Blade & Blade & Sting \\
\hline Baseline -Fins,Flaps & Sting/Blade & Blade & Blade & Sting \\
\hline Baseline -Fins,Flaps,Engine & Sting/Blade & Blade & $\angle C<$ & \\
\hline
\end{tabular}

*Unable to get high angle of attack range with sting mount. **All runs in Mach 20 Helium without vertical tails.

Table 3. Nominal Flow Conditions

\begin{tabular}{|l|c|c|c|c|c|}
\cline { 2 - 6 } \multicolumn{1}{c|}{ Facility } & Mach & $\mathbf{q}_{\infty}$ & $\mathbf{P}_{\mathbf{+}}(\mathbf{p s i})$ & $\left.\mathbf{T}_{\mathbf{I}} \boldsymbol{(}^{\circ} \mathbf{R}\right)$ & $\mathbf{R e} / \mathbf{f t}$ \\
\hline 20" Mach 6 Air & 6 & 2.0 & 125 & 910 & 2.0 \\
\hline 31" Mach 10 Air & 10 & 2.2 & 1450 & 1800 & 2.2 \\
\hline 20"Mach 6 CF4 & $6^{*}$ & 0.9 & 950 & 1150 & 0.4 \\
\hline 22" Mach 20 He & 20 & 1.7 & 1000 & 530 & 7.5 \\
\hline
\end{tabular}

*Mach 17-20 simulation due to increase in $\rho_{2} / \rho_{\infty}$

Table 4. Balance Matrix

\begin{tabular}{|c|c|c|c|c|}
\hline Balance & 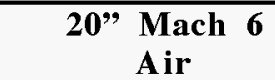 & $\begin{array}{c}\text { 31" } \\
\text { Mir }\end{array}$ & $\begin{array}{c}\text { 20" Mach } 6 \\
\text { CF } 4\end{array}$ & 22" $\underset{\text { Hech }}{\text { Me }}$ \\
\hline SS08 & Sting/Blade & Sting/Blade & Sting & \\
\hline $\mathrm{SS17A}$ & Sting/Blade & Sting/Blade & Blade & $\ddot{Z}$ \\
\hline 2045 & Sting & $\begin{array}{ll}2 \\
y\end{array}$ & Sting & $\mathrm{QPQ} \mathrm{Q} Z$ \\
\hline 2047 & $\mathrm{Zll} U$ & $2 Q$ & $\mathrm{Ell} U$ & Sting \\
\hline 2048 & Sting & $\ddot{Z}$ & $\mathrm{QEQ} Z$ & 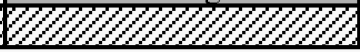 \\
\hline
\end{tabular}

Table 5. $\pm 0.5 \%$-Full Scale Balance Uncertainties

\begin{tabular}{|l|c|c|c|c|c|c|c|}
\cline { 2 - 8 } \multicolumn{1}{c|}{ Facility } & $\mathbf{q}_{\infty}$ & $\mathbf{C}_{\mathbf{N}}$ & $\mathbf{C}_{\mathbf{A}}$ & $\mathbf{C}_{\mathbf{m}}$ & $\mathbf{C}_{\mathbf{I}}$ & $\mathbf{C}_{\mathbf{n}}$ & $\mathbf{C}_{\mathbf{Y}}$ \\
\hline 20" Mach 6 Air & 2 & 0.02203 & 0.00441 & 0.00291 & 0.00143 & 0.00072 & 0.00441 \\
\hline 31" Mach 10 Air & 2.2 & 0.02003 & 0.00401 & 0.00264 & 0.00130 & 0.00065 & 0.00401 \\
\hline 20" Mach 6 CF4 & 0.9 & 0.02448 & 0.00490 & 0.00646 & 0.00159 & 0.00159 & 0.00490 \\
\hline 22" Mach 20 He & 1.7 & 0.01037 & 0.00181 & 0.00195 & 0.00067 & 0.00067 & 0.00207 \\
\hline
\end{tabular}

Based on highest full scale balance loads when data obtained from multiple balances 

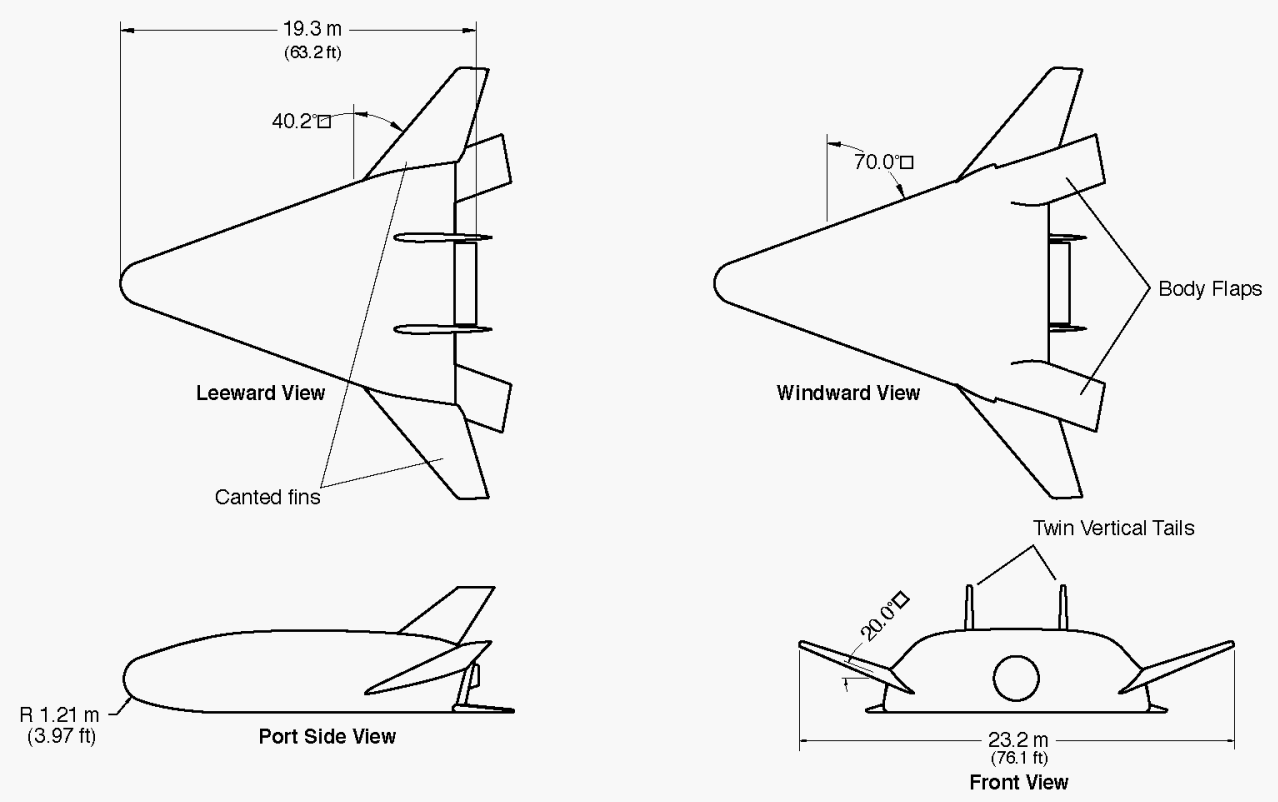

Figure 1. Sketch of Full-Scale X-33 604B0002F/G Configuration
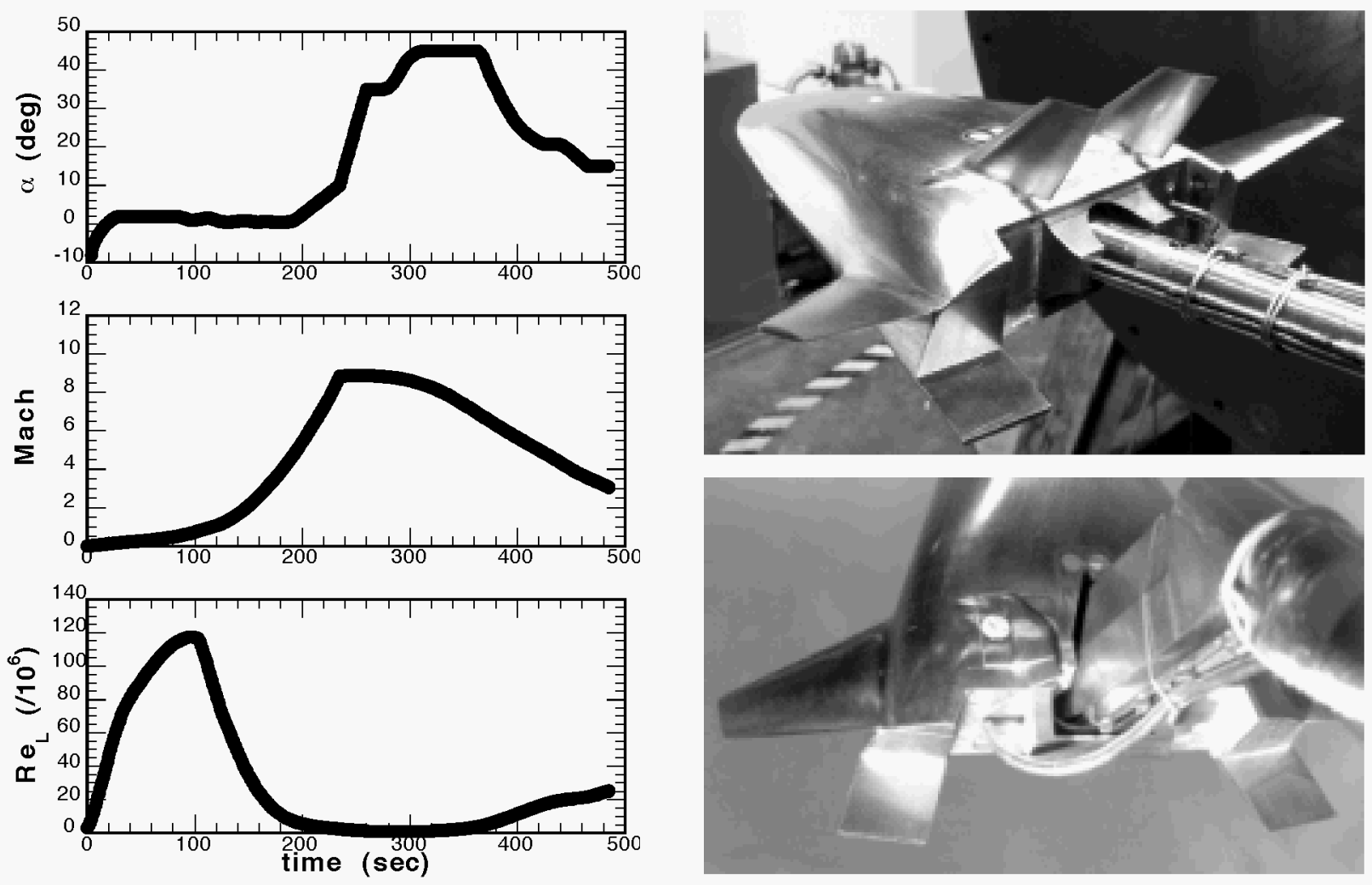

Figure 2. Typical X-33 Trajectory Parameters

Figure 3. Installation of $0.7 \% \mathrm{X}-33$ on Sting (top) and Blade (bottom) mounts in 31-Inch Mach 10 Tunnel 


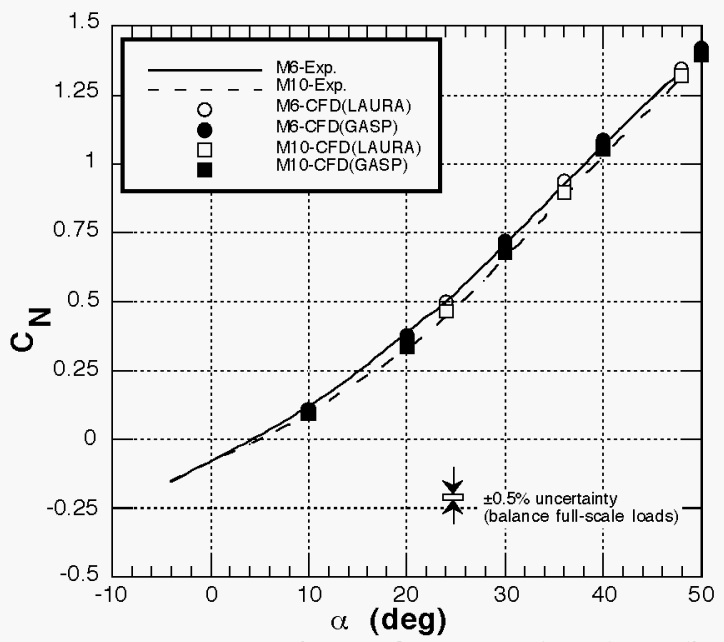

Figure 4(a). Comparison of Measured and Predicted Normal Force Coefficient for Mach 6 and 10

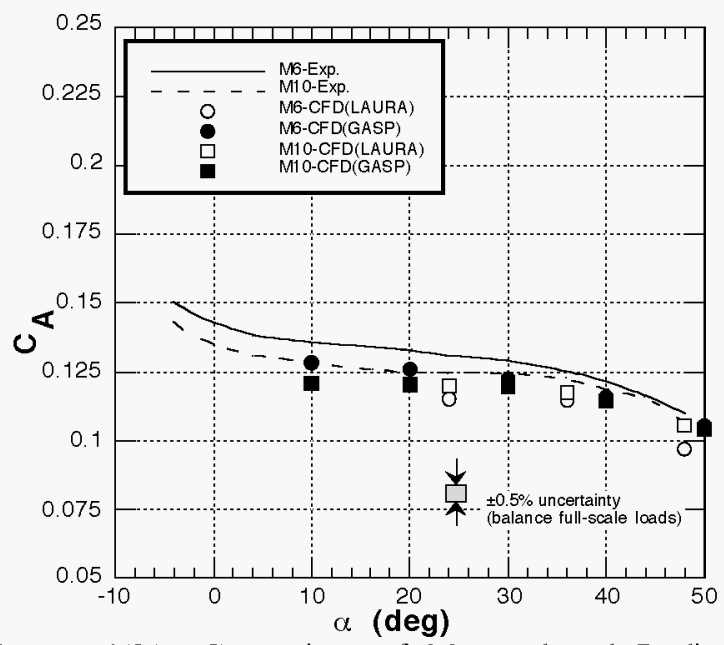

Figure 4(b). Comparison of Measured and Predicted Axial Force Coefficient for Mach 6 and 10

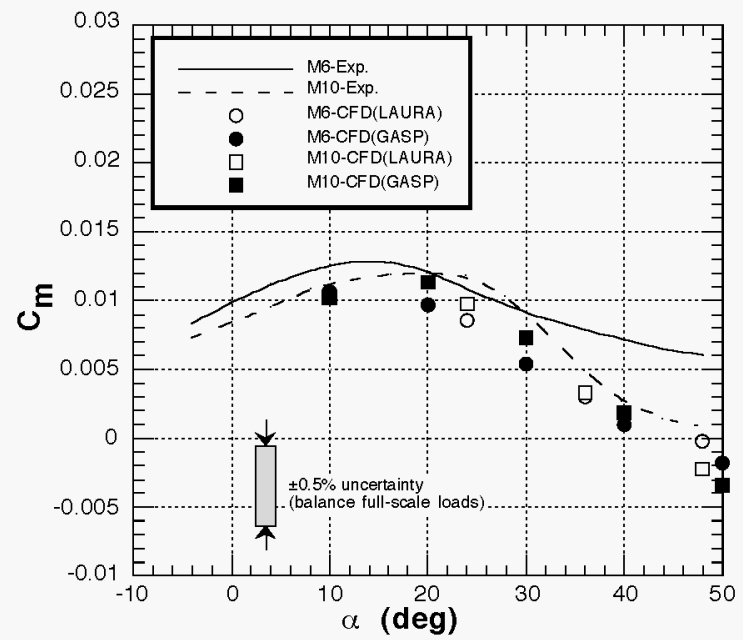

Figure 4(c). Comparison of Measured and Predicted Pitching Moment Coefficient for Mach 6 and 10

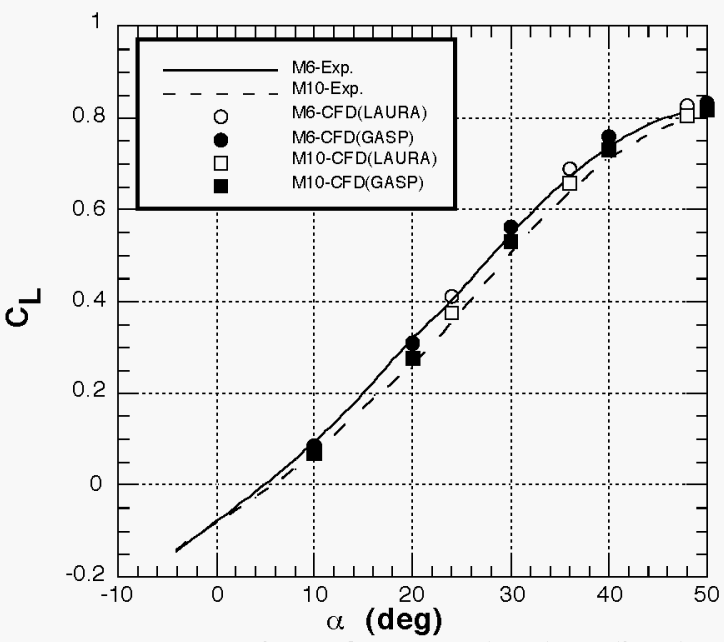

Figure 4(d). Comparison of Measured and Predicted Lift Coefficient for Mach 6 and 10

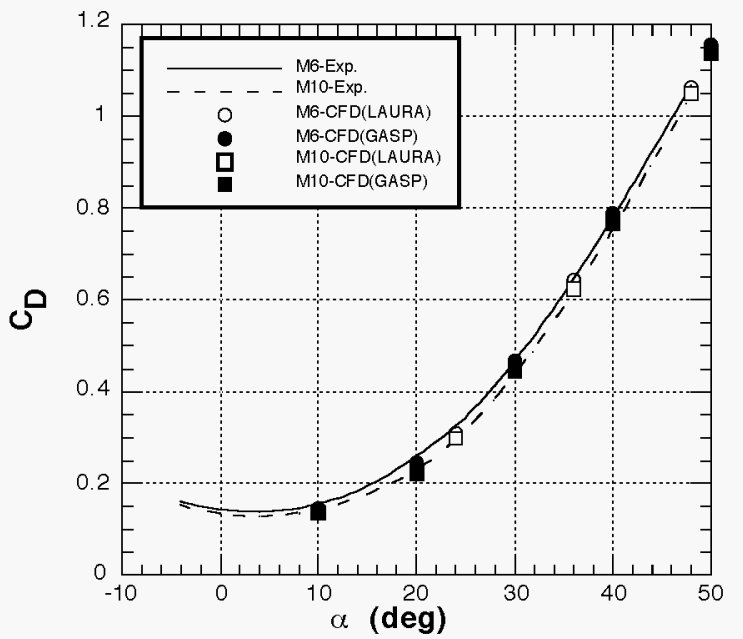

Figure 4(e). Comparison of Measured and Predicted Drag Coefficient for Mach 6 and 10

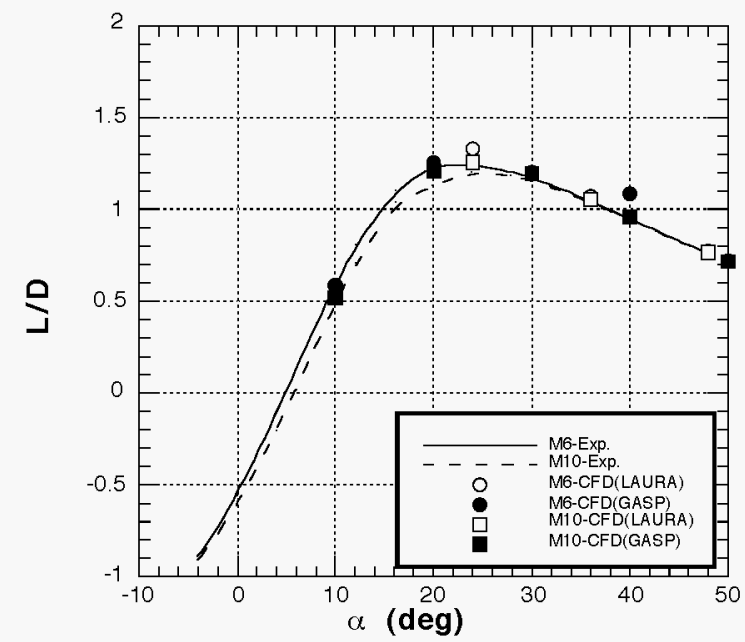

Figure 4(f). Comparison of Measured and Predicted Lift-to-Drag Ratio for Mach 6 and 10 


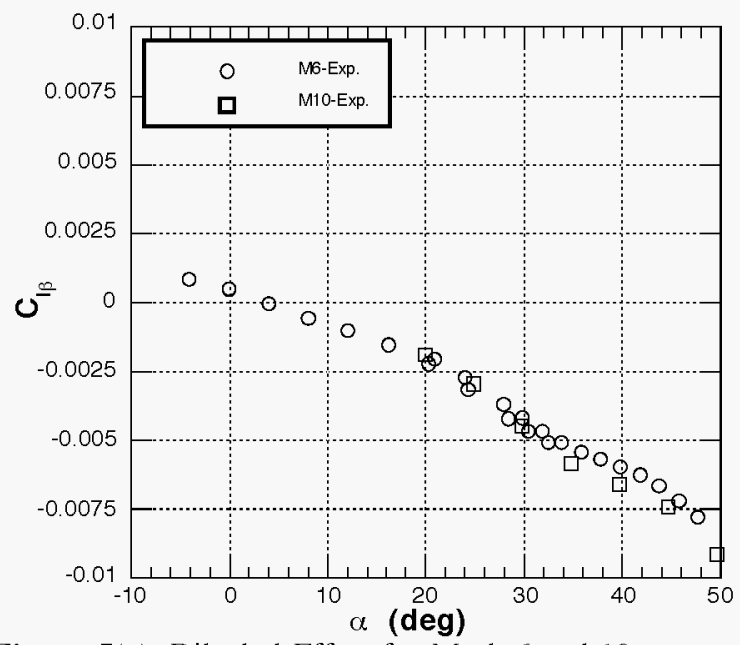

Figure 5(a). Dihedral Effect for Mach 6 and 10 Experimental Data

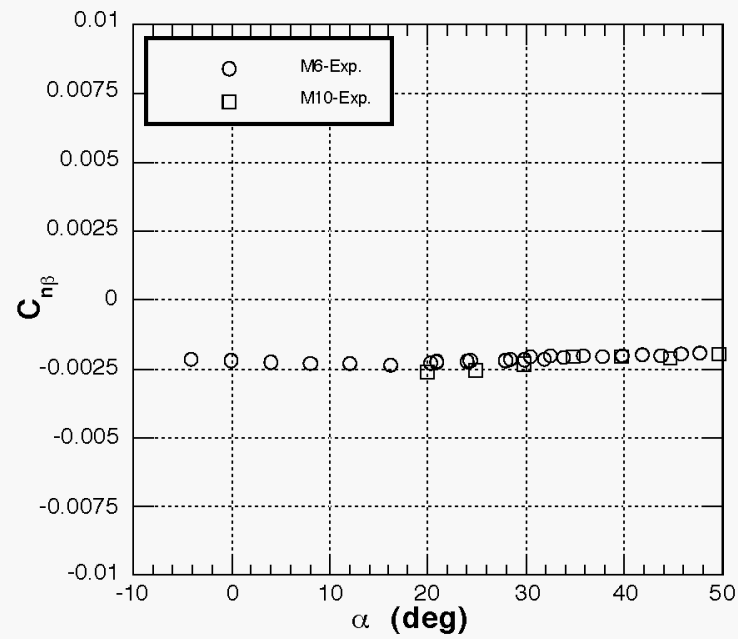

Figure 5(b). Directional Stability for Mach 6 and 10 Experimental Data

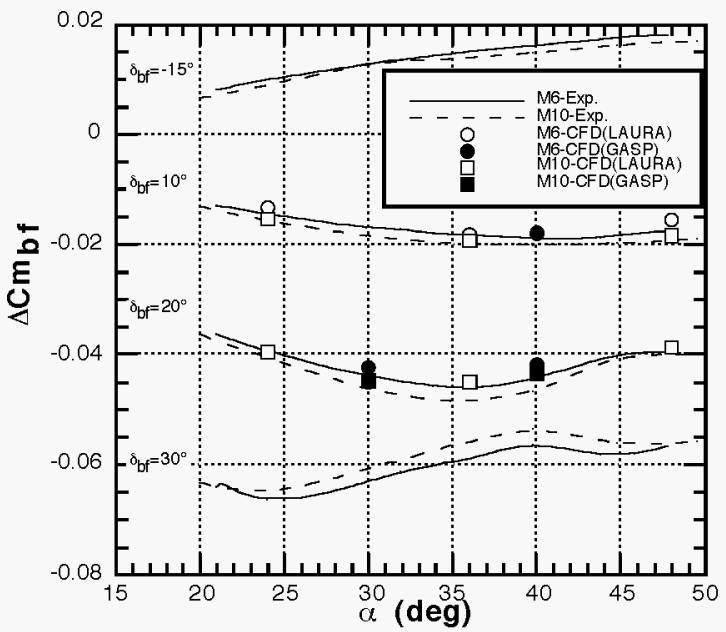

Figure 6(a). Comparison of Measured and Predicted Body Flap Control Authority for Mach 6 and 10

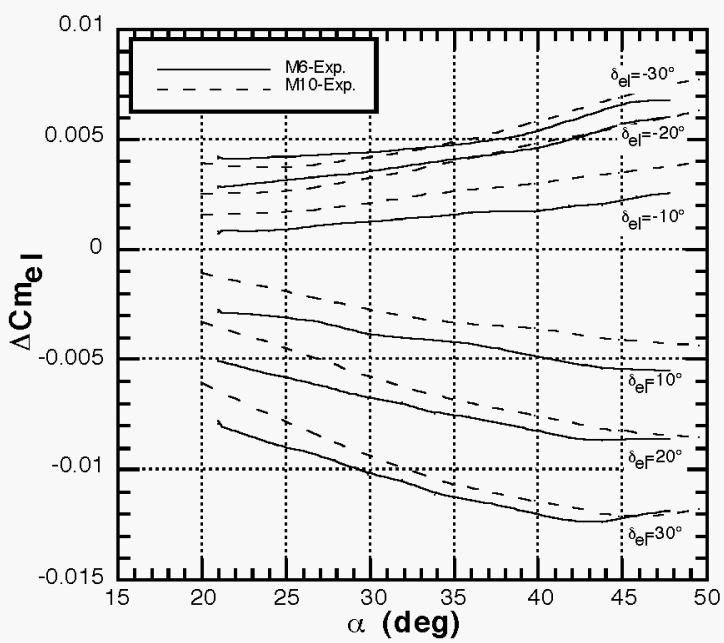

Figure 6(b). Measured Elevon Control Authority for Mach 6 and 10

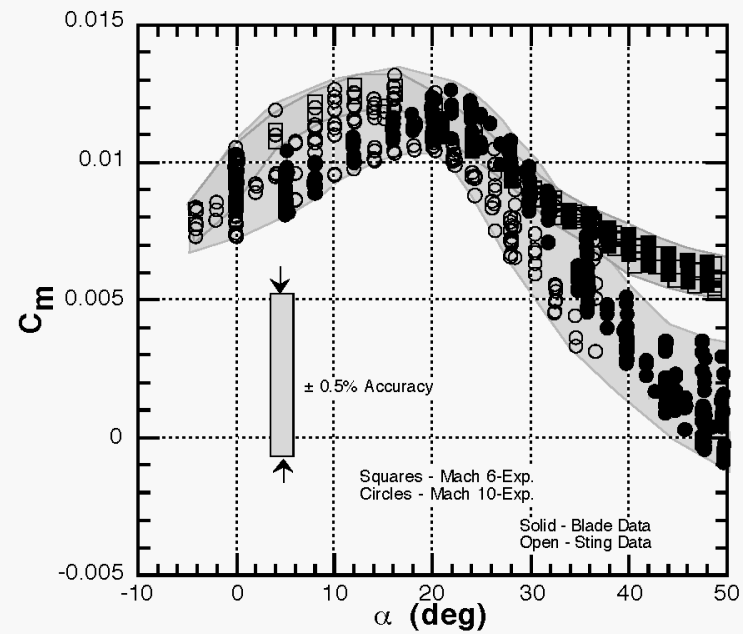

Figure 7(a). Repeatability of Mach 6 and 10 Experimental Data

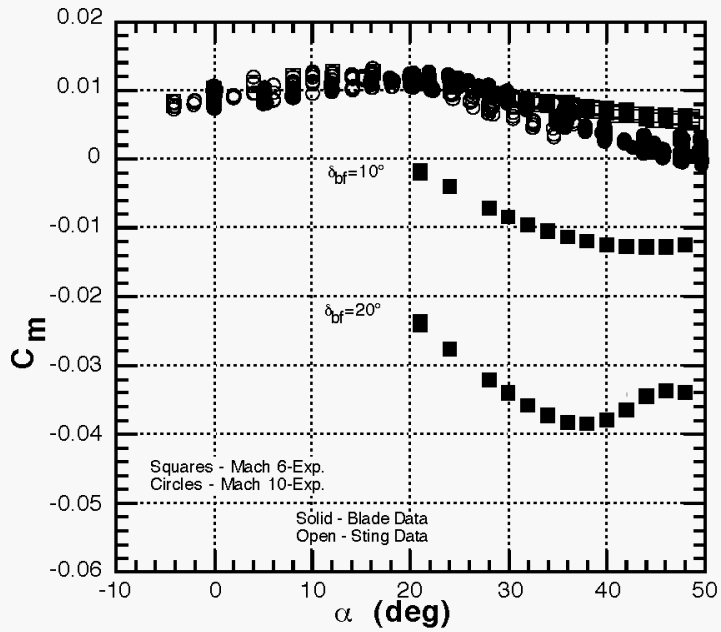

Figure 7(b). Measured Body Flap Control Authority Relative to Repeatability of Mach 6 and 10 Exp. Data 


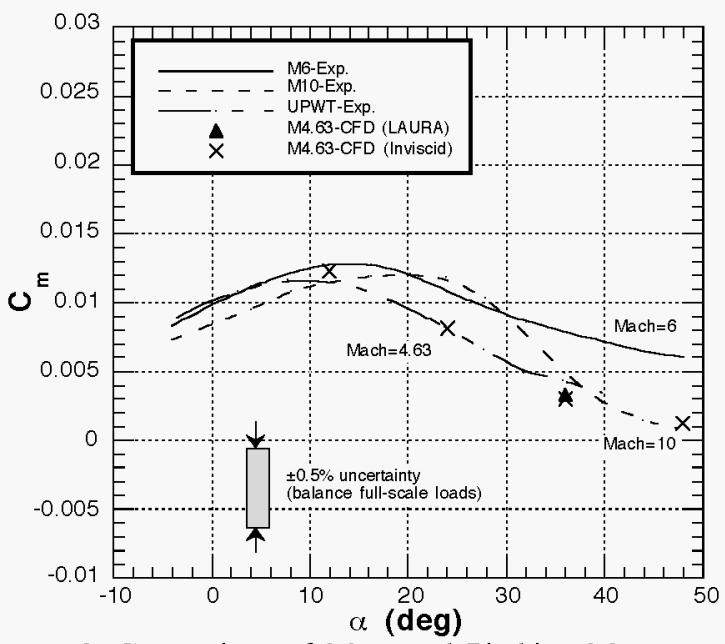

Figure 8. Comparison of Measured Pitching Moment Coefficient for Mach 4.63, 6, and 10

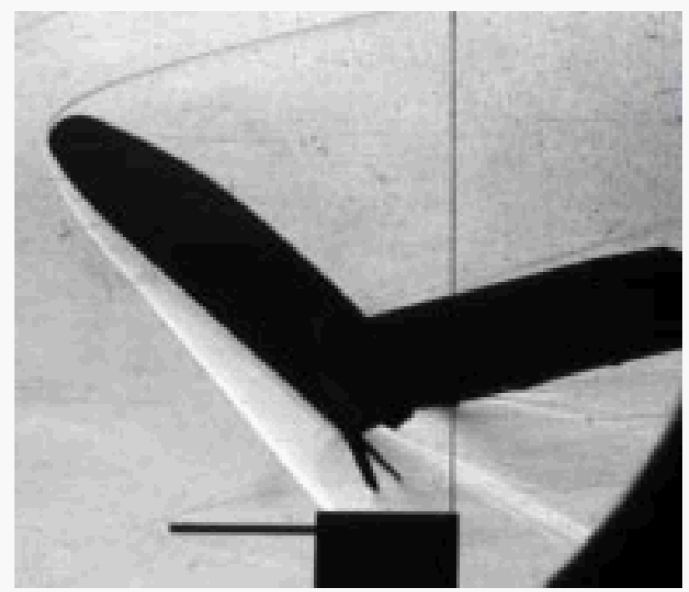

Figure 9(a). Schlieren photograph at $\alpha=48 \mathrm{deg}$ in 20-Inch Mach 6 Tunnel

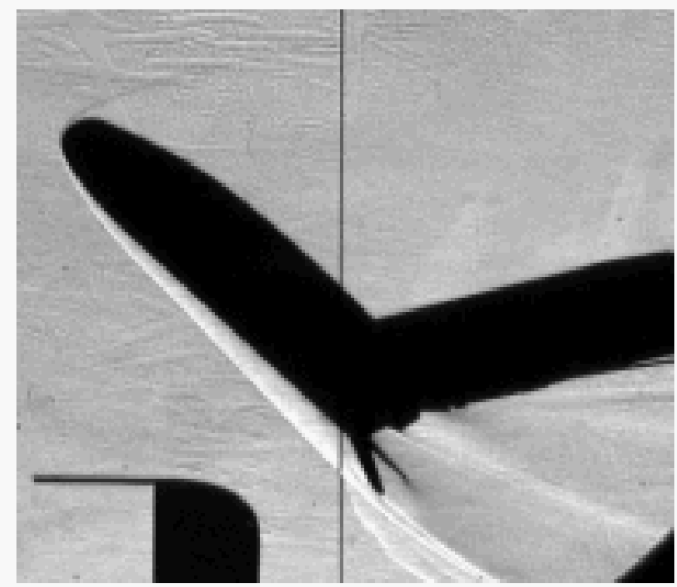

Figure 9(b). Schlieren photograph at $\alpha=48 \mathrm{deg}$ in 20-Inch Mach $6 \mathrm{CF}_{4}$ Tunne

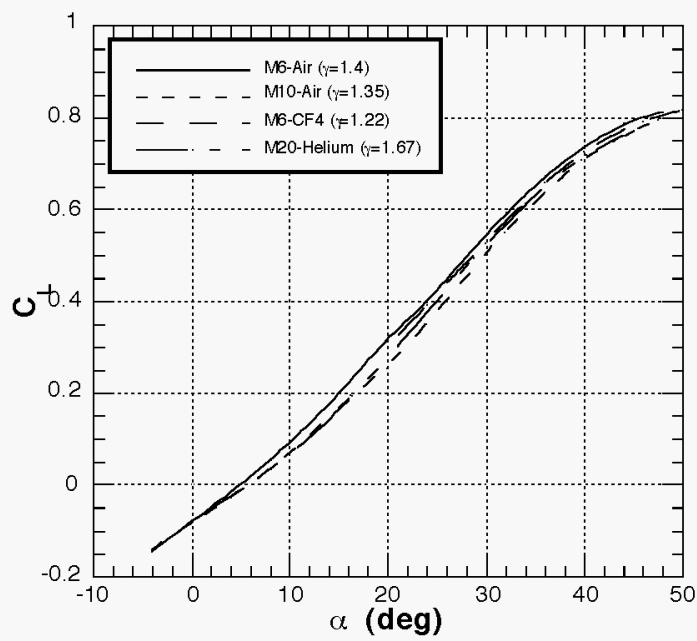

Figure 10(a). Effect of Mach Number and Shock Density Ratio on Measured Lift Coefficient

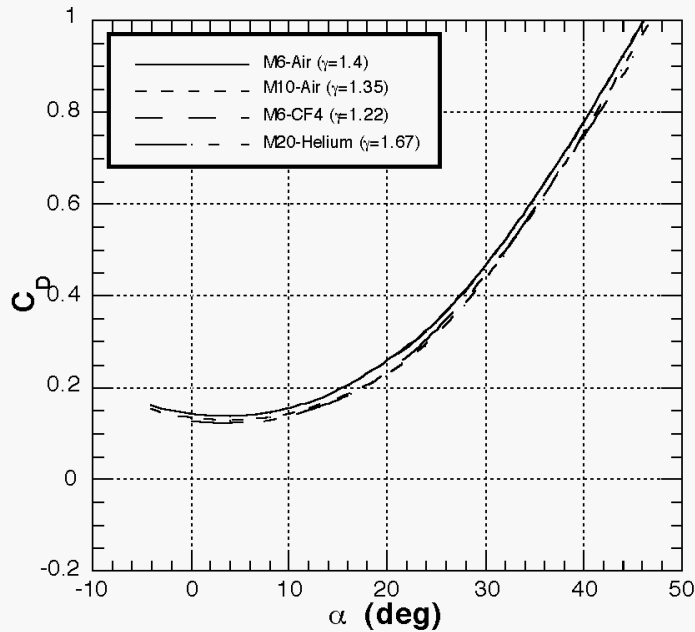

Figure 10(b). Effect of Mach Number and Shock Density Ratio on Measured Drag Coefficient

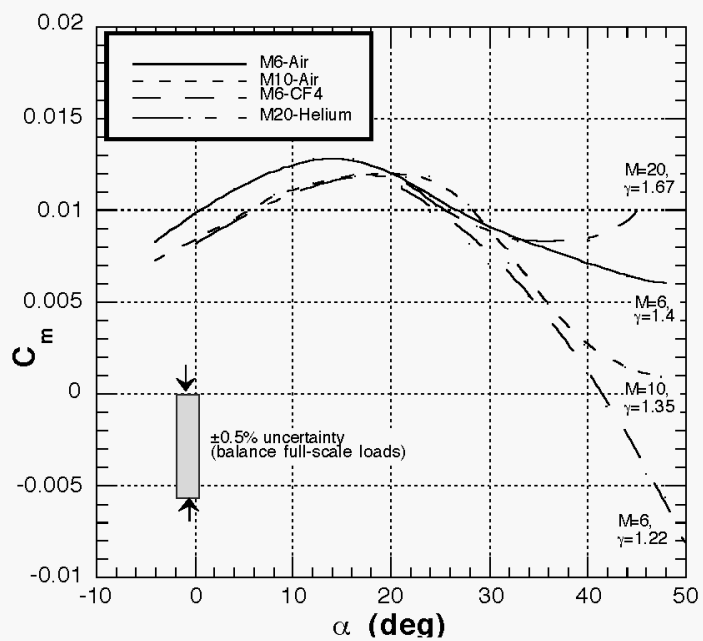

Figure 10(c). Effect of Mach Number and Shock Density Ratio on Measured Pitching Moment Coefficient. 


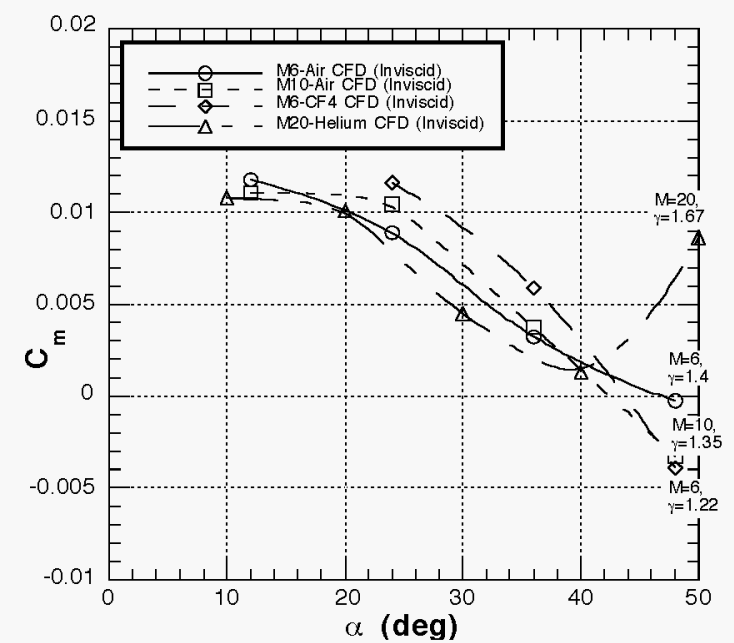

Figure 10(d). Effect of Mach Number and Shock Density Ratio on Predicted Pitching Moment Coefficient.

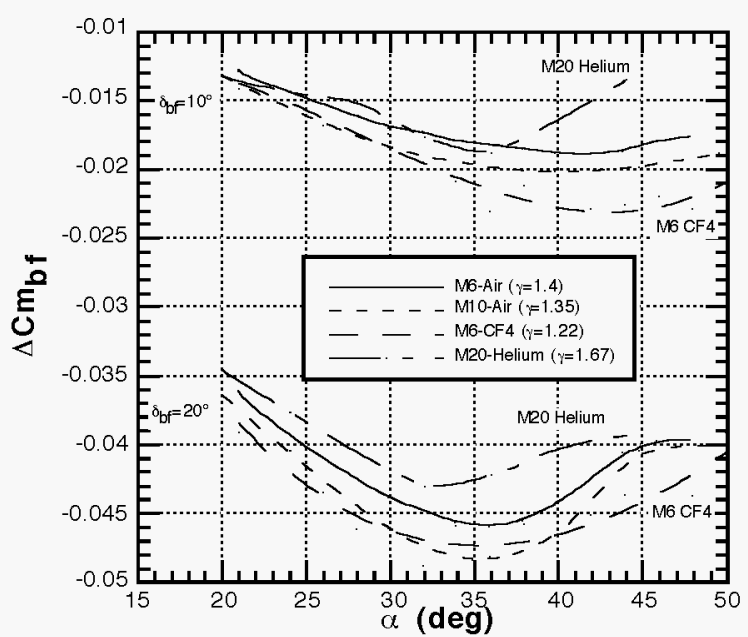

Figure 10(e). Effect of Mach Number and Shock Density Ratio on Measured Body Flap Control Authority

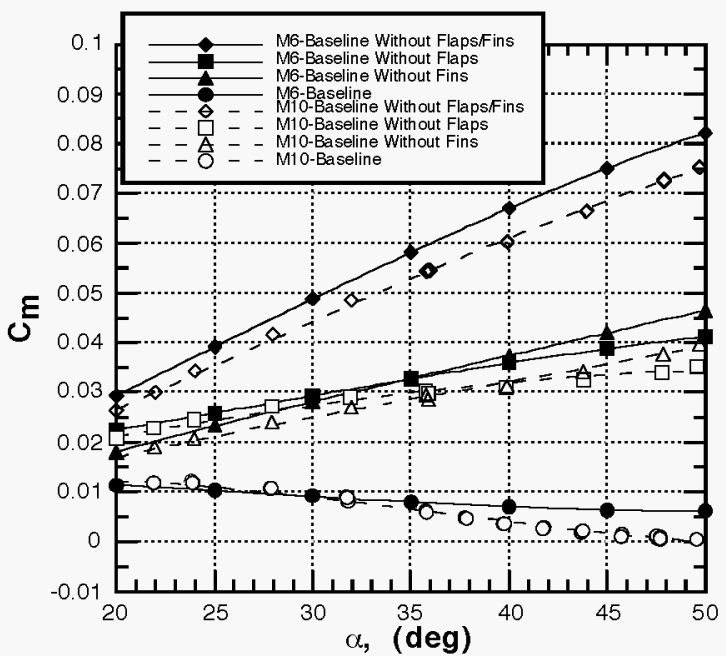

Figure 11. Comparison of Measured Pitching Moment Coefficient for Mach 6 and 10 for Configuration Build-Up Studies 